\title{
Chemical, biological, radiological and nuclear preparedness training for emergency medical services providers
}

\author{
Daniel Kollek, MD; ${ }^{*}$ Michelle Welsford, $\mathrm{MD}_{;}^{\dagger}$ Karen Wanger, $\mathrm{MDCM}^{\ddagger}$
}

\section{ABSTRACT}

Objective: We assessed the self-reported theoretical and practical preparedness training of Canadian emergency medical services (EMS) providers in chemical, biological, radiological and nuclear (CBRN) events.

Methods: We designed an online survey to address the theoretical and practical CBRN training level of prehospital providers. Emergency medical services staff in British Columbia and Ontario were invited to participate.

Results: Of the 1028 respondents, $75 \%$ were male, and the largest demographic groups were front-line personnel with more than 15 years of experience. Only $63 \%$ of respondents indicated they had received either theoretical or practical training to work in a contaminated environment, leaving $37 \%$ who indicated they had received neither type of training. Of those that had received any training, $61 \%$ indicated they had received "hands-on" or practical training and $82 \%$ indicated they had received some training in identification of a possibly contaminated scene. Only $42 \%$ had received training for symptoms of nerve agents, $37 \%$ had received training for symptoms of blister agents and $46 \%$ had received training for symptoms of asphyxiants. Thirty-two percent had received training for the treatment of patients exposed to nerve agents, and $30 \%$ had received training for the treatment of patients exposed to blister agents. Only $31 \%$ of all respondents had received training for detecting radiation.

Conclusion: CBRN events involve unique hazards and require specific education and training for EMS providers. A large proportion of Canadian EMS providers report not having received the training to identify and work in contaminated environments.

Keywords: CBRN, EMS, terrorism, PPE disaster preparedness, disasters, disaster planning, emergency medical services

\section{RÉSUMÉ}

Objectif: Nous avons évalué le degré de préparation théorique et pratique autodéclarée par le personnel des services médicaux d'urgence au Canada en cas de menaces chimiques, biologiques, radiologiques et nucléaires (CBRN). Méthodes : Nous avons conçu un questionnaire administré en ligne pour mesurer le degré de préparation théorique et pratique du personnel des services préhospitaliers en cas de menaces CBRN. Le personnel des services médicaux d'urgence de la Colombie-Britannique et de I'Ontario a été invité à y répondre.

Résultats : Parmi les 1028 répondants, $75 \%$ étaient de sexe masculin et les groupes démographiques les plus volumineux se composaient de personnel de première ligne cumulant plus de 15 années d'expérience. Soixante-trois pour cent seulement des répondants ont mentionné avoir reçu une formation théorique ou pratique pour travailler dans un milieu contaminé, les $37 \%$ restants ayant signalé n'avoir reçu ni I'une ni I'autre. Parmi ceux qui avaient reçu un type de formation, $61 \%$ ont indiqué avoir reçu une formation pratique ou concrète et $82 \%$ ont indiqué avoir reçu un type de formation pour la reconnaissance d'une zone potentiellement contaminée. Seulement $42 \%$ avaient reçu une formation relative aux symptômes occasionnés par les agents neurotoxiques, 37 \%, pour les symptômes occasionnés par les agents vésicants, et $46 \%$, pour les symptômes occasionnés par les agents asphyxiants. Trente-deux pour cent avaient reçu une formation sur les agents neurotoxiques et $30 \%$, sur les agents vésicants. Seulement $31 \%$ de tous les répondants avaient reçu une formation pour le dépistage des radiations.

Conclusion : Les accidents CBRN comportent des risques particuliers et requièrent une formation théorique et pratique particulière. Une proportion importante du personnel des services médicaux d'urgence au Canada signale ne pas avoir reçu la formation nécessaire pour reconnaître les milieux contaminés et pour y travailler.

\section{INTRODUCTION}

A large-scale toxic chemical release in a populated area has a high likelihood of leading to a mass casualty

\footnotetext{
*Clinical Associate Professor, †Associate Professor, Division of Emergency Medicine, McMaster University, Hamilton, Ont., †Medical Director, Regional Paramedic Base Hospital Program, Hamilton Health Sciences, Hamilton, Ont., ¥Clinical Associate Professor, Division of Emergency Medicine, University of British Columbia, and Regional Medical Director, British Columbia Ambulance Service, Vancouver, BC
}

Submitted Jul. 22, 2008; Revised Dec. 20, 2008; Accepted Jan. 21, 2009

This article has been peer reviewed.

CJEM 2009;11(4):337-42 
incident, which, in turn, would have a sizeable impact on the health care system. ${ }^{1,2}$ In order to save as many lives as possible in such events, on-scene medical triage and treatment is crucial. The challenge for emergency medical services (EMS), comprised of paramedics and fire first-responders, is a combination of the following: recognizing that a chemical, biological, radiological and nuclear (CBRN) event has occurred; providing resuscitative care in or near a potentially contaminated area; identifying the toxic agent to allow specific treatment with an antidote; and ensuring the safety of scene responders by avoiding contamination or cross-contamination throughout the events. Antidotes should ideally be delivered as quickly as possible, preferably on-scene. ${ }^{3-5}$

Emergency medical services providers are generally the only medical personnel at the scene and face the risk of primary exposure to biological agents, toxins or radiation. ${ }^{6}$ This requires a higher degree of protection than that required at the hospital against secondary exposure. Moreover, the facility can at times prepare for the arrival of victims; request decontamination and disrobing, ideally before arrival; and use isolation measures.

Experience with chemical disasters suggests that rescuers and emergency department staff should know the basic characteristics of chemical agent toxidromes and hold drills on prehospital triage, initial treatment and the transport of victims. ${ }^{7-9}$ Annual mock disaster exercises can improve decontamination, triage, on-scene medical care and victim transport. ${ }^{10}$

The issues surrounding CBRN agents are sufficiently different from other mass casualty situations to deserve special attention in planning and training.

Some countries have developed plans for the prehospital emergency response to conventional terrorist attacks, and to CBRN events. ${ }^{11-14}$ Three surveys published in 2007 evaluated the self-reported training of EMS providers for CBRN-type events in the United States and found that the rates of training were worryingly low. ${ }^{15-17}$ We could not locate an equivalent survey of Canadian EMS providers, and are aware of only a small number of specific CBRN teams in selected locations. We have previously studied Canadian hospital readiness for CBRN events, ${ }^{2}$ but no study describes the prehospital component. Our study assessed the perceived readiness of EMS personnel in British Columbia and Ontario to deal with CBRN events. We set out to answer the following 2 questions:

1. Have Canadian EMS staff been trained in the theory of CBRN-event response?
2. Have Canadian EMS staff received practical training in CBRN-event response?

\section{METHODS}

We performed a structured review of the literature using Ovid MEDLINE (1950 to present) and other nonindexed citations with the following search strategy: [Emergency Medical Services/, or Emergency Medical Technicians/, or Ambulances/ or prehospital.tw or paramedic\$.tw] AND [disasters/ or disaster planning/, or terrorism/, or CBRN.tw]. Based on this review, we designed a survey of the theoretical and practical CBRN training of EMS providers. The survey questions were then reviewed for applicability, clarity and validity by EMS staff in Ontario and British Columbia. Technical terms that might have been open to misinterpretation by respondents were clearly defined in the survey.

The final survey was posted on a website that was only accessible by individuals knowing its complex address. Emergency medical services providers were invited by email and posters to complete the survey. In Ontario, the survey invitations were distributed via e-mail by the Ontario Paramedic Association. In addition, posters were distributed in ambulance bases across the province. In British Columbia, the survey was distributed to both paramedics and fire first-responders. Paramedic members of the British Columbia Ambulance Service were reached through the provincial e-mail system. For fire first-responders, the survey invitation was sent to the Fire Chiefs' Association of British Columbia, who then distributed the information to its members (fire chiefs). Chiefs of each fire department in turn circulated the information to its members.

Respondents were asked to provide demographic information including their age, sex and years of experience. To maintain anonymity but allow the investigators to track multiple entries, the first half of the postal code and the last 3 digits of each respondent's telephone number were also collected.

In a previous study ${ }^{2}$ this method of data collection was effective for collecting and collating data from individuals at distant sites, which allowed the EMS crew members to provide information while away from the workplace (in the event that there might be a bias in their responses while supervised) and at any time of day or night (since the vast majority of EMS crews are shift workers).

To address CBRN training, we first asked the respondents, "Have you had either theoretical or practical training to work in a contaminated environment other than 
recognition of WHMIS [Workplace Hazardous Materials Information System] symbols?" We then asked if the training was theoretical only or whether it also included practical "hands-on" training. For those who had received practical training, we asked when they last practised putting on personal protective equipment (PPE) other than an N95 respirator or a similar mask (never, more than 1 year ago or in the past year), and whether they had ever

- practised performing procedures in $\mathrm{PPE}$;

- been mask-fit tested (for PPE other than N95);

- used a gas mask with a live agent;

- communicated face-to-face with someone other than their usual partner while wearing PPE;

- used radio or telephone communications while wearing PPE; or

- been called to provide actual care at a contaminated scene.

The survey next asked those respondents who reported having received theoretical training a number of CBRN-related questions. The first 8 of these questions asked when this training had taken place (in the past year, more than 1 year ago or never) and focused on personal protection and scene safety: how to identify a possibly contaminated scene, protocol and procedure for handling a possibly contaminated scene, decontamination of a patient at the scene, how to define "hot" and "cold" zones, when to use standard universal precautions, when and how to use PPE, and how to use standard universal precautions. The next 6 questions focused on recognition and management of patients with potential contamination: symptoms of nerve agents, blister agents and asphyxiants, treatment of nerve agents and blister agents, and the detection of radiation.

We defined "contaminated" as the presence of toxic chemicals, radiological material, or known highly infectious bacterial or viral agents requiring $\mathrm{PPE}$ beyond the level of standard universal precautions. We defined "PPE use" as any use of equipment at levels higher than universal precautions, and "standard universal precautions" as gloves, mask, protective eyewear and gown when indicated.

Data collection took place during 6 months between Jan. 9, 2006, and Jun. 15, 2006. The study was approved by the McMaster University Research Ethics Board.

\section{RESULTS}

There were 1028 respondents to the 28 -question survey. Most respondents were men, ranging in age from
36 to 50 years, with 16-22 years of experience, and were predominantly front-line personnel (Table 1).

Of 889 respondents with available data (14\% provided no answer), 329 (37\%) indicated they had never received either theoretical or practical CBRN training to work in a contaminated environment. In total, 364 (61\%) respondents reported they had received practical training and $236(39 \%)$ indicated it was theoretical only. Of those who had received practical training, only $50 \%$ had practised donning PPE (other than N95) in the last year, and another $32 \%$ indicated they had practised, but more than 1 year ago, and $14 \%$ had never had this opportunity.

Table 2 details the answers to the remaining practical training questions. About one-half of the respondents indicated that they had practised procedures in $\mathrm{PPE}$,

\begin{tabular}{|c|c|c|}
\hline Characteristic & No. (\%) of & respondents \\
\hline \multicolumn{3}{|l|}{ Age range, yr } \\
\hline $18-25$ & 75 & (7.3) \\
\hline $26-35$ & 285 & $(27.7)$ \\
\hline $36-50$ & 493 & $(48.0)$ \\
\hline$>50$ & 173 & (16.8) \\
\hline Other* & 1 & $(0.1)$ \\
\hline Did not respond & 1 & $(0.1)$ \\
\hline \multicolumn{3}{|l|}{ Sex } \\
\hline Male & 768 & $(74.7)$ \\
\hline Female & 245 & (23.9) \\
\hline Did not respond & 15 & (1.5) \\
\hline \multicolumn{3}{|l|}{ Credentials } \\
\hline EMR & 68 & (6.6) \\
\hline PCP & 566 & $(55.1)$ \\
\hline $\mathrm{ACP}$ & 127 & (12.4) \\
\hline $\mathrm{CCP}$ & 5 & (0.5) \\
\hline ALS, BLS, other & 237 & $(23.0)$ \\
\hline Did not respond & 25 & (2.4) \\
\hline \multicolumn{3}{|l|}{ Years of practice } \\
\hline $1-4$ & 206 & $(20.0)$ \\
\hline $5-10$ & 175 & $(17.0)$ \\
\hline $11-15$ & 161 & $(15.7)$ \\
\hline $16-22$ & 240 & (23.3) \\
\hline$>22$ & 233 & $(22.7)$ \\
\hline Did not respond & 13 & (1.3) \\
\hline \multicolumn{3}{|l|}{ Experience } \\
\hline Manager-supervisory & 84 & (8.2) \\
\hline Front line & 671 & (65.3) \\
\hline Both & 280 & $(27.2)$ \\
\hline Did not respond & 18 & (1.8) \\
\hline \multicolumn{3}{|c|}{$\begin{array}{l}\text { ACP = Advanced Care Paramedic; ALS = Advanced Life Support; BLS = Basic Life } \\
\text { SUpport; CCP = Critical Care Paramedic; EMR = Emergency Medical Responder; } \\
\text { PCP = Primary Care Paramedic. } \\
\text { *Respondents were given the options of "other" or to skip the question. }\end{array}$} \\
\hline
\end{tabular}


and that they had been mask-fit tested (for PPE other than the N-95 mask). Only about one-third indicated they had communicated face-to-face while wearing PPE as part of an exercise, and only one-quarter had practised radio or telephone communications. About 1 respondent in 5 reported training with a gas mask and a live agent. Of note, $40 \%$ of the respondents had been called to provide care at a contaminated scene.

Table 3 details the responses to the questions about

\begin{tabular}{|c|c|c|}
\hline Question & & $\begin{array}{l}\text { (\%) of "yes" } \\
\text { onses, }[95 \% \mathrm{Cl}]\end{array}$ \\
\hline $\begin{array}{l}\text { Have you practised performing } \\
\text { procedures in PPE? }\end{array}$ & 463 & (57.7) [54.3-61.1] \\
\hline $\begin{array}{l}\text { Have you been mask-fit tested } \\
\text { (other than N-95)? }\end{array}$ & 411 & (51.3) [47.9-54.8] \\
\hline $\begin{array}{l}\text { Have you ever used a gas mask } \\
\text { with a live agent? }\end{array}$ & 152 & (19.0) [16.3-21.7] \\
\hline $\begin{array}{l}\text { Have you used PPE in an exercise } \\
\text { involving face-to-face } \\
\text { communications between you and } \\
\text { someone other than your partner? }\end{array}$ & 263 & (32.9) [29.6-36.1] \\
\hline $\begin{array}{l}\text { Have you used PPE as part of a } \\
\text { larger exercise involving radio or } \\
\text { telephone communications? }\end{array}$ & 201 & $(25.1)$ [22.1-28.1] \\
\hline $\begin{array}{l}\text { Have you been called to provide } \\
\text { care at a contaminated scene? }\end{array}$ & 319 & $(40.0)[36.6-43.4]$ \\
\hline
\end{tabular}

theoretical training. Of those who had received theoretical training, $82 \%$ indicated they had received training in how to identify a possibly contaminated scene at some time, and $78 \%$ had received training on the protocol and procedure for handling a possibly contaminated scene. Fifty-nine percent had received training on the decontamination of patients at a scene and $73 \%$ had received training on the definitions of "hot" and "cold" zones. In contrast, nearly all respondents reported training on how (97\%) and when (95\%) to use standard universal precautions. Almost all respondents also indicated that they had received training on how $(92 \%)$ and when $(94 \%)$ to use PPE.

The majority of respondents had not received any theoretical training on the symptoms, treatment and detection of several CBRN agents. For nerve agents, the percentage of respondents who had never received training on symptoms was $58 \%$ and treatment was $68 \%$. For blister agents, the percentages were $63 \%$ and $70 \%$. For asphyxiants, $54 \%$ had never received training on symptoms. Last, only $31 \%$ of respondents had ever received training on the detection of radiation.

\section{DISCUSSION}

The results of this survey show significant gaps and variability in EMS training for CBRN events, both on a theoretical and practical level. Although nearly one-half of the respondents reported being called to provide care

Table 3. Theoretical training of 893 respondents who indicated having ever received theoretical chemical, biological, radiological and nuclear training to work in a contaminated environment

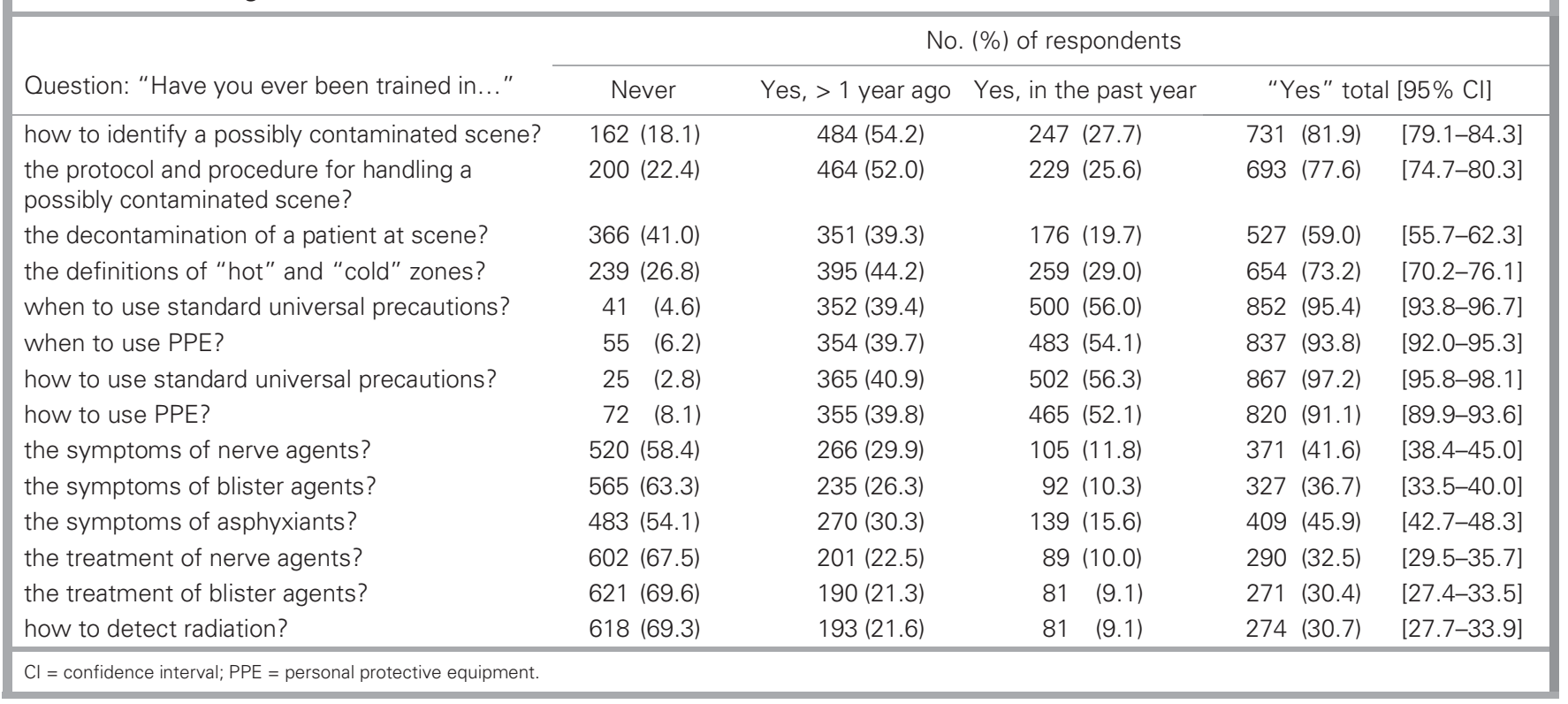


at a contaminated scene, less than one-third had trained to provide care while in PPE. Scene and provider safety are the basic first steps in any response. Deficiencies in such safety can lead to casualties within the responder ranks, and has the potential to magnify the original event into a mass casualty scene. In the case of CBRN events, an inability to recognize, to remain safe and to provide proper decontamination at the scene can also lead to contamination of hospitals, as was seen in the sarin attacks in the Tokyo subway system in 1995.7

Our survey did not ask if the respondent was a member of a CBRN team. At the time of the survey, such teams were rare with less than $1 \%$ of EMS crews involved. Deployment of a CBRN team can only occur after a scene is identified as potentially contaminated. Even if there were a team available, the deployment delay requires that non-CBRN team first-responders perform the initial assessment. Identification of a contaminated scene requires training, as specifically addressed in the survey.

All EMS personnel train for multicasualty incidents, such as motor vehicle collisions or building collapses. Responding to such incidents requires an approach, education and skills that differ from the usual singlepatient call. The ability to function effectively under unusual circumstances requires repeated and specialized training. Although CBRN events commonly involve multiple patients and thus, on the surface, might resemble multicasualty incidents, the unique hazards of CBRN events require specific education and training. The addition of a potential CBRN agent to any situation significantly changes the flavour of that situation and therefore the reactions of personnel at the scene. Many of the responders to this survey had not received any instruction on how to identify a contaminated scene, or how to decontaminate patients. One respondent in 3 had received neither theoretical nor practical training to work in a contaminated environment. Although it would be impractical to train all EMS providers in any given province to the CBRN advanced level, all first-responders should be trained to identify a potentially hazardous scene, to ensure their own safety and to trigger a higher level response.

Scenes involving CBRN will likely be managed by multiple agencies concurrently, each of which will have a unique approach to the situation. Ideally, these agencies must interface without difficulty based on previous agreements and training. Issues involving communications, equipment, and command and control must be resolved and practised.
Awareness of the risks inherent in a situation and knowledge of appropriate PPE are the foundations of safety for responders. Personal protective equipment beyond the level of universal precautions is not simple to don and doff properly and requires repeated practice. Improper donning may lead to gaps or leaks in the equipment and therefore a risk of contamination. Improper doffing may lead to secondary contamination from agents on the surface of the equipment. Although nearly all of the respondents had received theoretical training about when and how to use PPE, only one-half had practised donning PPE in the past year, and 1 in 7 had never had this opportunity.

The results of this survey identify a significant lack of preparedness for situations involving a CBRN agent. Surveys taken in the United States that asked paramedics about perceived preparedness for terrorist events or events from weapons of mass destruction showed similar results. ${ }^{15-17}$

In Canada, at the federal level, there is infrastructure for planning and training; however, the "trickle down" to the local level has not been substantial. The Canadian Emergency Management College trains teams in combined CBRN response, but this is a slow process. Most specialized CBRN response teams in Canada are the result of local or provincial initiatives, or both, making use of the federal resources in a "train the trainer" model. The Canadian Emergency Management College now provides an online course in basic awareness, but the authors were unable to determine how many agencies avail themselves of this opportunity. Initial and ongoing educational curricula should be designed to include the important topics about contaminated environments, CBRN recognition, safety and patient management, and should be created in a manner that allows agencies to provide the training to large numbers of providers in-house. There is a need to push the training to the front lines. Checklists are a good tool to ensure that details are communicated. CBRN readiness checklists may help first-response agencies to determine what additional education is required.

\section{Limitations}

A key limitation to our study was our inability to determine the true denominator for the results. In Ontario, there are approximately 6000 EMS personnel (i.e., primary, advanced and critical care paramedics); however, there is no e-mail distribution list for all of these personnel. This survey was distributed primarily to the 
1200 members of the Ontario Paramedic Association via their distribution list. In British Columbia, the survey was distributed to both paramedics and fire firstresponders. In British Columbia, there are 3400 primary and advanced care paramedics to whom the survey was sent. There is no single database for fire first-responders in British Columbia (overall estimates range from 4800 to 7200 province-wide), so dissemination of the survey was dependent on the support of EMS leadership to forward the survey to their personnel on our behalf.

The project was restricted to Ontario and British Columbia, because in some cases EMS leaders in other provinces objected to the collection of this information. The reasons for their objections included concern that questions about CBRN preparedness might trigger demands for increased training and equipment and run counter to the plans of the organization.

We described the responders' perception of their training. However, we did not investigate the actual training programs that were delivered to each group of responders. A responder's perception of his or her training may be more accurate, and therefore more important, than the on-paper description of the training within the organization. This could be thought of as a limitation, but may in fact be a strength of the study.

\section{CONCLUSION}

CBRN events involve unique hazards and require specific education and training. As assessed with this survey, many Canadian EMS providers have not been trained to identify and work in contaminated environments. When untrained providers are called to respond to a contaminated scene, their lack of knowledge, training and practice threatens the safety of patients, EMS and hospital staff, and the health care system.

Competing interests: None declared.

\section{REFERENCES}

1. Brennan RJ, Waeckerle JF, Sharp TW, et al. Chemical warfare agents: emergency medical and emergency public health issues. Ann Emerg Med 1999;34:191-204.

2. Kollek D. Canadian emergency department preparedness for a nuclear, biological or chemical event. CJEM 2003;5:18-26.
3. Krivoy A, Layish I, Rotman E, et al. OP or not OP: the medical challenge at the chemical terrorism scene. Prebospital Disaster Med 2005;20:155-8.

4. Karayilanoglu T, Kenar L, Gulec M. Evaluations over the medical emergency responding to chemical terrorist attack. Mil Med 2003;168:591-4.

5. Baker D. Civilian exposure to toxic agents: emergency medical response. Prehospital Disaster Med 2004;19:174-8.

6. Krivoy A, Rotman E, Layish I, et al. Medical management in the chemical terrorism scene [article in Hebrew]. Harefuab 2005;144(4):266-71, 302.

7. Tokuda Y, Kikuchi M, Takahashi O, et al. Prehospital management of sarin nerve gas terrorism in urban settings: 10 years of progress after the Tokyo subway sarin attack. Resuscitation 2006;68:193-202.

8. Keim ME. Terrorism involving cyanide: the prospect of improving preparedness in the prehospital setting. Prehospital Disaster Med 2006;21(Suppl 2):s56-60.

9. Kenar L, Karayilanoglu T. Prehospital management and medical intervention after a chemical attack. Emerg Med J 2004;21:84-8.

10. FitzGerald DJ, Sztajnkrycer MD, Crocco TJ. Chemical weapon functional exercise-Cincinnati: observations and lessons learned from a "typical medium-sized" city's response to simulated terrorism utilizing Weapons of Mass Destruction. Public Health Rep 2003;118:205-14.

11. Carli P, Telion C, Baker D. Terrorism in France. Prehospital Disaster Med 2003;18:92-9.

12. Okumura T, Ninomiya N, Ohta $M$. The chemical disaster response system in Japan. Prehospital Disaster Med 2003;18: 189-92.

13. Beaton RD, Johnson LC. Instrument development and evaluation of domestic preparedness training for first responders. Prehospital Disaster Med 2002;17:119-25.

14. Tucker JB. National health and medical services response to incidents of chemical and biological terrorism. JAMA 1997; 278:362-8.

15. Chaput CJ, Deluhery MR, Stake CE, et al. Disaster training for prehospital providers. Prehosp Emerg Care 2007;11:458-65.

16. Reilly MJ, Markenson D, DiMaggio C. Comfort level of emergency medical service providers in responding to weapons of mass destruction events: impact of training and equipment. Prehosp Disaster Med 2007;22:297-303.

17. Clawson A, Menechemi N, Kim U, et al. Are we ready for terrorism? Emergency medical technicians' and paramedics' training and self-perceived competence since September 11. Am 7 Disaster Med 2007;1:26-32.

Correspondence to: Dr. Daniel Kollek, McMaster University, 4000 Creekside Dr., Unit 902, Dundas ON L9H 7S9; kollek@ceep.ca 